\title{
Conf-941013--25
}

UCRL-JC-118714

PREPRINT

\section{GEM Detector Conductor Manufacturing Experience}

\author{
N. N. Martovetsky, J. R. Pace, P. J. Reardon, D. E. Richied, R. J. Camille, \\ P. G. Marston, B. A. Smith, G. A. Deis, J. S. Bohanan, J. H. Gersten, J. L. Heck, \\ L. N. Howell, S. C. Robinson, and H. Marti
}

This paper was prepared for submittal to the IEEE Transactions on Applied Superconductivity and the Applied Superconductivity Conference Boston, MA

October 16-21, 1994

October 7, 1994

This is a preprint of a paperintended for publication in a joumal or proceedings. Since changes may be made before publication, this preprint is made available with the understanding that it will not be cited or reproduced without the permission of the author. 


\section{DISCLAIMER}

This doxument was prepared as an account of work sponsored by an agency of the Lnited States Government. Neither the United States Government nor the University of California nor any of their employees, makes any warranty, express or implied, or assumes any legal liability or responsibility for the accuracy; completeness, or usefulness of any information. apparatus, product, or process disclosed, or represents that its use would not infringe privately owned rights. Reference herein to any specific commercial products, process, or service by trade name. trademark, manufacturer, or otherwise, does not necessarily constitute or imply its endorsement, recommendation, or favoring by the United Stales Government or the University of California. The riens and opinions of authors expressed berein do not necessarily state or reflect those of the United States Goverament or the University of California. and shall not be used for advertising or product endorsement purposes. 


\section{DISCLAIMER}

Portions of this document may be illegible in electronic image products. Images are produced from the best available original document. 


\title{
GEM DETECTOR CONDUCTOR MANUFACTURING EXPERIENCE
}

\author{
Nicolai N. Martovetsky ${ }^{+}$James R. Pace, Paul J. Reardon and Donald E. Richied \\ SSC Laboratory ${ }^{*}, 2550$ Beckleymeade Avenue, Dallas, TX 75237 \\ Richard J. Camille, Peter G. Marston and Bradford A. Snith \\ MIT Plasma Fusion Center, 185 Albany Street, Cambridge, MA 02139
}

Gary A. Deis

Lawrence Livermore National Laboratory*, PO Box 808, Livermore, CA 94550

\author{
Jeff S. Bohanan, John H. Gertsen, Jack L. Heck, L. Neville Howell, and Samuel C. Robinson \\ Martin Marietta Energy Systems, PO Box 2009, Oak Ridge, TN 37831 \\ Hanspeter Marti \\ Marti Supratec, Burglistrasse 33, CH-8034 Wallisellen, Switzerland
}

\begin{abstract}
Feasibility studies and manufacturing experience on the GEM Magnet conductor are presented, including all components - NbTi strand, cable, conduit manufacture, cable pulling, and aluminum sheath application.
\end{abstract}

\section{INTRODUCTION}

The GEM Detector Magnet[1], planned to be built at the SSC, employed cable-in-conduit conductor. The innovative feature of this conductor design, outer protective shunt, was never manufactured before at this size.

This paper discusses the experience gained during manufacture of prototypes of the GEM Conductor and numerous feasibility studies.

Although the GEM Detector will not be built as the SSC project was terminated, we believe that the GEM Conductor design philosophy will be used in other future projects as a highly stable conductor with good mechanical properties and

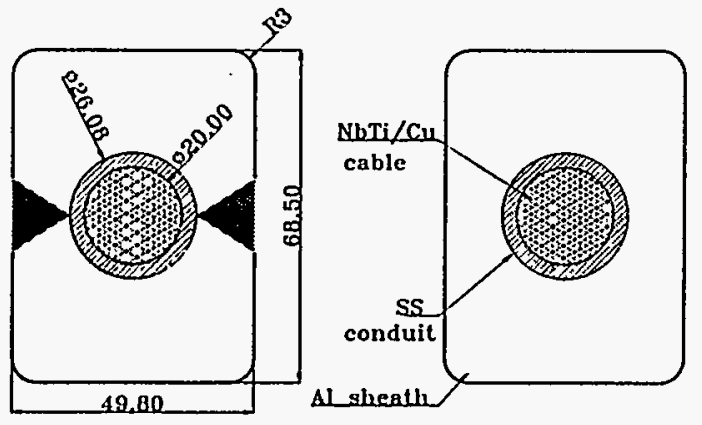

Figure 1. Cross section of the GEM Conductor. Dimensions are in mm. Two options shown: welded sheath (left) and coextruded (right)

Manuscript is received October 17, 1994.

+Present address is PO Box 808,LLNL, Livermore, CA 94550

- This work was supported by the U.S. Department of Energy under Contract No. DE-AC35-89ER40486 and LLNL Contract No. W-7405-Eng-48. safe protection performance. The cross sections of two options for the GEM conductor are shown in Fig. 1 and a detailed description of the conductor parameters and rationale for the design ane given in [1].

\section{MANUFACTURE OF THE CONDUCTOR PROTOTYPE}

The R\&D and verification program on the GEM Magnet included a test of the conductor and joints in the GEM Test Coil (about $70 \mathrm{~m}$ of the conductor) prior to the construction of the GEM Magnet.

\section{A. Strand}

The main parameters of the strand are given in [1]. The requirements are well within the industrial capability. The strand for the GEM Test Coil was delivered by IGC Advanced Superconductors, Inc. Several prototypes meeting the specification were also manufactured by Bochvar Institute, Moscow, Russia.

\section{B. Cable}

The cable is fully transposed, 4-stage right-hand twisted, made of 450 strands. The cabling pattern is $6 \times 5 \times 5 \times 3$. The final cable is wrapped with 304 SS tape $0.05 \mathrm{~mm}$ thick with a $40-50 \%$ overlap. Cable weight per $1.2 \mathrm{~km}$ long piece is about $1920 \mathrm{~kg}$. The last stage of cabling was the most difficult because of the heavy weight of the spools and also because of the unstable configuration of 6 subcables. It was solved differently at New England Electric Wire, where round subcables were sized by a die, then fixed by SS tape and at Kirs Cable, Russia where last stage subcables were preshaped similar to [2] prior to final sizing.

We studied the change of RRR in copper in composite strands during cabling. Initial RRR was in the range of $190-$

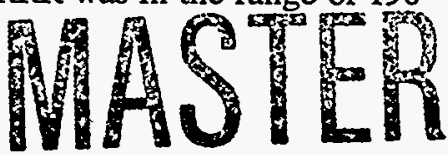


220. The degradation of RRR in the strand after each stage of cabling was measured and the results are shown in Table 1.

TABLE 1.

EFFECT OF CABLING ON COPPER RRR IN STRANDS

\begin{tabular}{|c|c|c|c|}
\hline Conditions & $\begin{array}{l}\text { Samples } \\
\text { measured }\end{array}$ & $\begin{array}{l}\text { RRRmin/RRR } \\
\max \end{array}$ & $\begin{array}{l}\text { RRR } \\
\text { average }\end{array}$ \\
\hline after $1^{\text {sin }}$ stage & 4 & $133 / 158$ & 146 \\
\hline after $2^{\text {nd }}$ stage & 4 & $133 / 152$ & 137 \\
\hline after $3^{\text {rd }}$ stage & 4 & $127 / 152$ & 139 \\
\hline after 4rd stage & 12 & $125 / 155$ & 139 \\
\hline $\begin{array}{l}\text { annealed, after cabling, } \\
\text { short samples }(2 \mathrm{~cm})\end{array}$ & 12 & $170 / 232$ & 198 \\
\hline $\begin{array}{l}\text { after } 4 \text { rd stage annealed, } \\
40 \mathrm{~cm} \text { long samples* }\end{array}$ & 6 & $169 / 176$ & 171 \\
\hline
\end{tabular}

It was found that there is a variation of RRR not only among samples but along the length of one continuous wire after cabling. The final annealing restores RRR of copper to the specification requirements, so when very high $R R R$ $(>130)$ is specified for $\mathrm{NbTi}$ cables, the cabling needs to be followed by a restoring anneal.

\section{Conduit}

For the GEM Test Coil Conductor fabrication we chose a pull-through method, which promised better insurance that the conduit will be leak tight, as it dramatically reduces the length of the welds and eliminates possibility of overheating $\mathrm{NbTi}$ which can cause degradation of the critical current, and allow good access for tests/inspections. The drawback of this approach is that a long length assembly line is needed.

We chose grade TP $304 \mathrm{~L}$ material because of good weldability. For better reproducibility of the automated welding, requirements for the chemical composition of ASME Specifications SA-213 were amended as Al<0.01\%, S within $0.006-0.007 \%, \mathrm{~S}+\mathrm{P}<0.03 \%$, because of lack of penetration on the samples with low $S$ content [3]. The final ID of the conduit with a cable inside was $20 \mathrm{~mm}$ with a wall thickness of $3.04 \mathrm{~mm}$ to take the quench pressure safely. To provide sufficient clearance for the cable $(20.15 \pm 0.15 \mathrm{~mm}$ OD) pulling and relatively easy reduction by drawing through a die, seamless tubes were used for the GEM Test Coil, $28.58 \mathrm{~mm}$ OD with $3.05 \mathrm{~mm}$ wall.

Welding of the conduit segments was performed in two passes. The root pass was done using automatic orbital GTAW tube welder with no filler wire. Second pass was done with automatic orbital GMAW tube welder, because trials to perform the weld with GTAW orbital welder only were successful with $2.5 \mathrm{~mm}$ wall thickness but resulted in apparent decrease of the wall thickness with $3 \mathrm{~mm}$ wall.

After welding the conduit was inspected visually both from inside with a boroscope and outside, then thermally shocked 3 times with liquid nitrogen. No drop-in was allowed from the inside to ease the pulling operation. Afterwards, the butt weld joint was helium leak checked with a fixture clamped to the outside of the conduit with a leak sensitivity better than
$10^{-9} \mathrm{mbar} * \mathrm{I} / \mathrm{s}$. Welds were checked with dye penetrant for surface cracks. Then outer surface was finished for UT of the weld. We did not try an eddy current inspection; eddy current was not a very sensitive NDE in the past for cable-in-conduit $[4,5]$. Ultrasonic inspection was somewhat more promising, but needed more work to enhance sensitivity [5]. Our experience showed that the material inhomogeneity in the weld region did not allow to give clear flaws evaluation, at least on the level of less than $10 \%$ of the wall thickness due to the austenitic grain structure of the welds.

After the conduit was assembled, it was hydraustatically tested at a pressure of 240 bars for 1 hour with no indication of leaks or pressure decay.

\section{Pulling the cable into the conduit}

It was known, that pulling a cable inside the conduit was feasible on several tens or even hundreds meters lengths $[2,6]$. Extensive feasibility study of pulling a cable into a conduit has been performed [7] for the GEM Conductor $(1200 \mathrm{~m}$ long). Presented below is a summary of these studies.

The work was done on the Westinghouse cable for the LCT program, with similar wrap of the SS tape and with SS tube, providing $0.62 \mathrm{~mm}$ radial gap between the cable and a conduit (in the GEM conductor case the gap was about 1.09 $\mathrm{mm}$ nominally). Weight per unit length was comparable (17 $\mathrm{N} / \mathrm{m}$ for LCT Westinghouse Cable, $15 \mathrm{~N} / \mathrm{m}$ for the GEM cable). A $30 \mathrm{~m}$ long conduit was assembled from segments with mechanical alignment on the OD and chamfers at ID with no welds.

The first four runs were standard and cable was returned back by pulling the cable in opposite direction through the conduit. The $5^{\text {th }}$ and $6^{\text {th }}$ runs were made with vibration of the conduit by air hammers. Run 7 was done with isopropyl alcohol used as a lubricant wetting the cable as it was entering the conduit. Then 3 more vibration assisted runs were performed with another cable. Results of the measurements for 4 first runs are shown in Table 2.

An observed increase in the friction force is thought to result from the damaged foil and/or loosening the cable. The $3^{\text {rd }}$ test was done to see the difference between the sliding and static friction by stopping the pulling. No change in friction force when resume pulling was observed. Tiny metallic chips and powder were seen on the SS tape, indicating some wear.

TABLE 2.

RESULTS OF THE CABLE PULLING TESTS

\begin{tabular}{|l|l|l|l|}
\hline Test No & Length of pull $(\mathrm{m})$ & Pull load $(\mathrm{N} / \mathrm{m})$ & Friction coeff. \\
\hline 1 & 30.5 & 10.64 & 0.63 \\
\hline 2 & 30.5 & 10.64 & 0.63 \\
\hline 3 & 18.3 & 18.67 & 1.10 \\
\hline 4 & 17.7 & 21.60 & 1.28 \\
\hline
\end{tabular}

Two pull tests were done with vibration of the conduit. A small pneumatic hammer impacted wooden blocks $5 \times 10 \mathrm{~cm}$, that were held against the middle of the first $6 \mathrm{~m}$ segment of 
the conduit. When vibration was applied, the friction coefficient for the same cable used in the previous tests dropped from 1.28 to 0.83 . In the next trial the same cable was pulled $7.2 \mathrm{~m}$ without vibration and then $6.7 \mathrm{~m}$ with vibration; friction coefficients were 1.94 and 0.56 , respectively.

Wetting by isopropyl alcohol gave the friction coefficient of 1.49 which showed that it was not helpful.

After these tests, a new cable was used for vibration assisted experiments. This time vibration was provided by two air hammers through the aluminum bars attached to the pipe at 6 and $12 \mathrm{~m}$ from the tube inlet. Three sequential runs showed friction coefficients of $0.36,0.57$ and 0.64 . This clearly indicates, that vibration is a very simple and effective means to reduce the friction coefficient.

A wear study was done by pulling the cable back and forth to simulate $1134 \mathrm{~m}$ of the sliding. These conditions are in fact more severe than for unidirectional pulling. Localized wear was observed, but no copper was visible through the foil. The most relevant measurement of the friction force was done during the pulling of $75 \mathrm{~m}$ cable inside the conduit for the GEM Test Coil. The pulling force was $711 \mathrm{~N}$ which gives a friction coefficient of 0.6 which is only slightly higher than stainless steel against stainless steel friction coefficient (0.55).

So, for roughly $1200 \mathrm{~m}$ of the GEM full length conductor with $20 \mathrm{kN}$ weight we can expect that the pulling force would not exceed $13 \mathrm{kN}$ or $70 \mathrm{MPa}$ which is not dangerous either from the point of view of breakage or from affecting the RRR of copper, which starts for annealed oxygen free copper at around $130 \mathrm{MPa}[8]$.

This showed that pulling the GEM cable inside a conduit should have been safe and feasible with no risk for lengths of $1200 \mathrm{~m}$. From strength considerations even pulling a $2 \mathrm{~km}$ cable looks feasible. Wear should be considered carefully for longer lengths or heavier cables.

\section{E. Compacting the cable-in-conduit}

The CICC was compacted down to the specified void fraction of $38 \%$ by overdrawing through a die. Preliminary tests showed that the drawing force was quite low - about 26 $\mathrm{kN}$ [9]. Wall thickness after the overdrawing did not change and the conduit elongated proportionally to the reduction of the cross section which implies that when cable-in-conduit is reduced after the whole length of the cable is encased, the far end of the cable should not be restricted to allow the cable to slide inside the conduit. Otherwise the cable will be stretched together with the conduit. No significant heating was observed during overdrawing $\left(47^{\circ} \mathrm{C}\right.$ in the cable).

A somewhat higher force during overdrawing was measured in reducing the $75 \mathrm{~m}$ of the cable-in-conduit for the GEM Test Coil - $40 \mathrm{kN}$ but also showed that the overdrawing is feasible with a moderate size winch.

After the overdrawing, the welds were visually inspected and UT tested. No defect was found, but minimum detectable defect in heat affected zone was about $0.25 \mathrm{~mm}$, at least order of magnitude worse than in bulk tube. Afterwards they were He leak tested with sensitivity better than $5 e-10 \mathrm{mbar} * 1 / \mathrm{s}$ and all welds passed. Total amount of butt welded joints overdrawn during manufacturing studies was about 20 and no damage to the joints during overdrawing was observed.

Pressure drop measurements (2-10 bar pressure drop) at room temperature showred accordance with theoretical friction factor for laminar flow within 5-30\% with better fit at lower bound.

\section{F. Aluminum sheath assernbly}

- Two options for manufacturing of the aluminum sheath were pursued - welded from two symmetrical profiles and coextruded over the conduit (Fig. 1). The welded sheath option was employed for manufacture of the $75 \mathrm{~m}$ long GEM Test Coil, while extrusion feasibility studies were undertaken by Cables Cortaillod, Cortaillod, Switzerland.

\section{F1. Welded on sheath}

A three pass GMAW welding process was established to maintain the temperature in the cable space below $320^{\circ} \mathrm{C}$. Several welded samples with perforated conduit about 3 feet long each were leak tight with better than 1e-9 mbar*1/s leak rate, which showed that Al sheath weld can be made leak tight. No noticeable crack growth was detected after thermocycling the sample between $300 \mathrm{~K}$ and liquid nitrogen temperature 30 times.

Electrical transition length between the cable and the conduit was measured to be $0.38 \mathrm{~m}$ at room temperature. This indicates that in the event of a quench, current will be transferred to the sheath fast enough without risk of overheating the cable.

Welding procedure was developed, welders and welding equipment were certified, QC inspectors oversight provided. Nevertheless, after the conductor welding, grinding and GEM Test Coil winding the following defects were disovered:

1. Conduit was burned through during the $\mathrm{Al}$ sheath welding in several places.

2. The aluminum sheath leaked. In addition to several pin holes in the sheath weld it was permeable to He gas in many places due to porosity.

This does not necessarily mean that the welded sheath can not be built safely, but it shows that the risk of this process is high.

\section{Coextruded sheath}

The temperature of the aluminum in the deformation zone reaches $400-550{ }^{\circ} \mathrm{C}$, depending on the particular process, which causes a concern about damage of the temperature sensitive NbTi. It was known, that directly aluminum clad cables could be produced with degradation of the critical current of 5-7\% or less. In the case of the GEM Conductor 
we anticipated somewhat lower temperature but longer exposure to high temperature, because of the heavier cross section and lower extrusion speed. Another potential risk in this process is the coextrusion press stoppage. On the other hand, advantages of this method are lower cost, higher reliability of having secondary containment around the conduit, good mechanical contact with the conduit, better potential consistency of the geometrical dimensions. All those issues were addressed in the feasibility studies made at Cables Cortaillod.

Two thermocouples per sample were inserted inside the conduit, about $75 \mathrm{~mm}$ apart, underneath the stainless steel wrap and temperature measured during the runs. The highest temperature was recorded in the worst conditions of simulation of the emergency stop. Even though this was extremely rare event (once per several years), it was worth while considering, keeping in mind the very high cost of the conductor. Fig.2 shows the temperature profile of the typical runs, including intentional stop and one of the slowest runs at $0.1 \mathrm{~m} / \mathrm{min}$. At the maximum speed $-1.0 \mathrm{~m} / \mathrm{min}$, maximum temperature was $280^{\circ} \mathrm{C}$. As it is known, $350^{\circ} \mathrm{C}$ for $10 \mathrm{~min}$ causes $I_{c}$ degradation less than $5 \%$ (see for example[5]), coextrusion at Cortaillod proved to be safe for all modes of operation including emergency stop as in this case temperature in the extrusion chamber falls fast enough.

As a result of the $R \& D$ at Cortaillod, the final outside dimensions varied -height $- \pm 0.2 \mathrm{~mm}$, width $- \pm 0.15 \mathrm{~mm}$, concentricity of the tube inside the profile- $\pm 0.3 \mathrm{~mm}$. Temperature measurement show good consistency with data taken in the first run.

Even though minimal adjustment of the process needs to be done before production, these results leave no doubt that the process developed at Cables Cortaillod is superior to all considered for application of the aluminum sheath on the conduit for the GEM Conductor and similar applications.

\section{CONCLUSION}

Experience gained in feasibility studies on GEM Conductor fabrication showed that:

1.Process of NbTi CICC cabling may require additional annealing of the cable after the final cabling if requirements for RRR are higher than approximately 130 .

2. Pulling the cables into the conduit with the lengths of $1 \mathrm{~km}$ or more is feasible with small radial gaps $(0.5-1.5 \mathrm{~mm})$. Vibration was very helpful during the pulling of the cable.

3 . Overdrawing the conduit with about $10 \%$ reduction requires very moderate force.

4. Heat affected zone in the weld area makes it difficult to achieve a high UT resolution.

5.Welded option of the application of the $\mathrm{Al}$ sheath on CICC was developed, but proved to be risky.

6. Coextrusion of the aluminum sheath on the CICC was developed for heavy aluminum cross sections with good

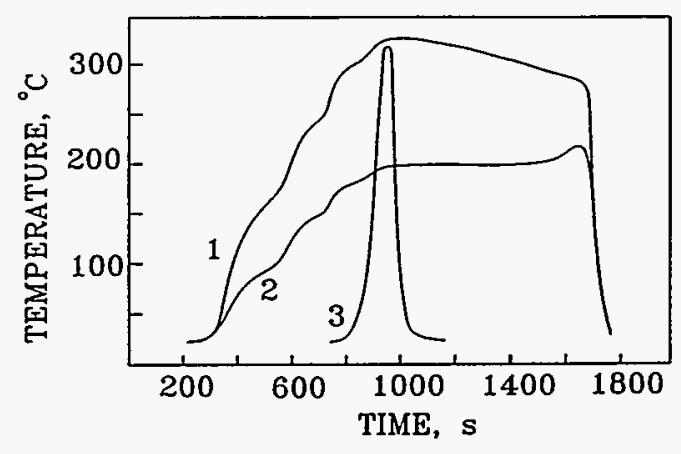

Fig.2. Typical cable temperature profiles for coextrusion trials. 1) Thermocouple No.1 in the intentional stop trial; 2) Thermocouple No.2 in the same run; 3) $0.1 \mathrm{~m} / \mathrm{min}$ continuous run

dimensional consistency and low temperature in the cable during sheath application.

\section{ACKNOWLEDGMENTS}

The authors would like to express their gratitude to:

S. Pourrahimi, MIT/PFC, G. Naumovich, Everson Electric Co.; A. Nikulin and coworkers from Bochvar Institute and Kirs Cable, Russia; W.F. Thompson, R.L. Huddleston, R.E. Pollard, MMES, Oak Ridge, F.Vogel, J. Prod'hom and C. Pierrehumbert, Cables Cortaillod. We are especially grateful to Prof. Frederick Gilman, SSCL for his strong support of the GEM Magnet Project and conductor development.

\section{REFERENCES}

[1]. J. Minervini, P. Marston, R. Camille et al, "Conductor Design for the GEM Detector Magnet," SSCL preprint 348, May 1993, also presented at ISSC5, San Francisco, 5-8 May 1993

[2]. D. Bessette, D.Ciazynski, P. Decool, et.al. "Fabrication and Test Results of the $40 \mathrm{kA}$ CEA Conductors for NET/TER", Proc. of the $17^{\text {th }}$ SOFT Conference, Roma, Italy, 1992, p.788-791.

[3]. A.A. Shirali and K.C. Mills, "The Effect of Welding Parameters on Penetration in GTA Welds". Welding Journal, AWS, July 1993, Welding Research Supplement I p. 347-353.

[4]. M. Steeves, QA/QC for US DPC coil, Personal communication

[5]. J.Rauch, D.Salathe, F.Konig, H.P. Marti, SSC/GEM Detector Conductor Report, ABB, Report N HISM 20469, Zurich, Oct.15, 1992.

[6]. A. Bonito Oliva, S. Ceresara, A. della Corte, et al, "Statusof the Euroatom ENEA $0.6 \mathrm{~m} 12 \mathrm{~T} \mathrm{Nb}_{3} \mathrm{Sn}$ Magnet: Manufacturing Experience of the CIC conductor and Test Results on a Model Coil" , Proc. of the $17^{\text {th }}$ SOFT Conference, Roma, Italy, 1992, p.793-796.

[7]. W.F. Thompson, RL. Huddleston, R.E. Pollard, S.C. Robinson, Cable in Conduit Pulling Development for the super conducting SuperCollider GEM Detector Magnet, March 31, 1993, SSCL, GEM Technical Note GEM-TN94-598.

[8]. H. Buchna Proceedings of the Second International Conference on Magnet Technology, Oxford, Rutherford Lab, 1967, p.305-312

[9]. G. Naumovich, D.Rakos, Personal communication. 